\title{
The Prevalence of Parasitic Human Intestinal Helminthes and the Efficacy of Anthelmintic Drug in Children in Uzo-Uwani Local Government Area, Enugu State, Nigeria
}

\author{
Cletus Anes Ukwubile ${ }^{1,2^{*}}$, Otalu Otalu Jr., ${ }^{3}$, Uduak Akpabio ${ }^{3}$, Matthew Onyema Agu ${ }^{2}$ \\ ${ }^{1}$ Department of Pharmacognosy, Faculty of Pharmacy, University of Ibadan, Ibadan, Nigeria \\ ${ }^{2}$ Department of Basic and Applied Sciences, Federal Polytechnic, Bali, Nigeria \\ ${ }^{3}$ Department of Veterinary Public Health, Faculty of Veterinary Medicine, Ahmadu Bello University, Zaria, Nigeria \\ Email: *doccletus@yahoo.com
}

Received July 24, 2013; revised August 23, 2013; accepted August 30, 2013

Copyright (c) 2013 Cletus Anes Ukwubile et al. This is an open access article distributed under the Creative Commons Attribution License, which permits unrestricted use, distribution, and reproduction in any medium, provided the original work is properly cited. In accordance of the Creative Commons Attribution License all Copyrights (C) 2013 are reserved for SCIRP and the owner of the intellectual property Cletus Anes Ukwubile et al. All Copyright (C) 2013 are guarded by low and by SCIRP as a guardian.

\begin{abstract}
Introduction: A study on the current status of parasitic intestinal helminthes and the efficacy of anthelmintic drug was carried out among primary school pupils at Community Primary School Ogurugu, Uzo-Uwani Local Government Area, Enugu State. Objectives: The research was conducted in order to determine the prevalence of human intestinal helminthes among primary school pupils, and also to determine the prevalence in relation to age and sex, and to check the efficacy of anthelmintic drug (Levamisole) on the worms, in Ogurugu Uzo-Uwani Local Government Area, Enugu State, Nigeria. Methods: A total of 242 faecal samples were collected randomly from the school children and analyzed using standard parasitological procedures. Results: Data obtained showed an overall prevalence of 143 (59.1\%) out of 242 samples and that the efficacy of anthelmintic drug Ergamisole ${ }^{\circledR}$ (Levamisole R12564; Unicure Pvt.ltd India) 50 mg in reducing the worm burden was 99 (82.5\%) in 120 samples treated. Age related prevalence and efficacy of anthelmintic varied across the sample groups. There was no significant difference in sex related infections in the sample group $(\mathrm{P}>$ $0.5)$. The efficacy of the drug reduces with the increase in age. Also the efficacy of Levamisole drug in reducing the worm burden were hookworm 59 (89.5\%), Ascaris 24 (85.7\%), Trichuris 26 (78.6\%) while Taenia and Strongyloides showed drug resistance. This indicates that a single dose of the medication is not enough for total elimination of these endo parasites. Conclusion: The study revealed that poor hygienic practices as well as unsanitary conditions were responsible for high prevalence recorded in the area, and advocated health education through primary health care and mass deworming of primary school children as control measures.
\end{abstract}

Keywords: Prevalence; Anthelmintic; Levamisole; Children; Ascaris lumbricoides; Trichuris trichiura

\section{Introduction}

Parasitic helminthes are distributed throughout the world with high prevalence in poor and socio-economically deprived communities in the tropics and subtropics [1]. Ascariasis and trichiuriasis are among the top ten most common diseases in the world [2]. These diseases continue to be a global health problem, particularly among children in poor communities in developing countries [3]. If AIDS is synonymous with promiscuity, helminthes infections are synonymous with poverty [4]. Epidemio-

*Corresponding author. logical assessment of these infections has traditionally focused on estimating the number of infections (Prevalence) which occur worldwide. This is because the clinical consequences of these infections are very mild [5].

Helminthes parasites of importance to man are Enterobius vermicularis (Pinworm), soil transmitted helminthes (STH), Ascaris lumbricoides (roundworm), Trichuris trichiura (whipworm), Necator americanus, Ancylostoma duodenale (Hookworms) and Strongyloides stercoralis (threadworm) [6-8]. With the exception of $E$. vermicularis, intestinal trematodes and cestodes, most of the common intestinal helminthes infections of man are faecal-borne infections and the transmission occurs either 
from hand to mouth or directly through food and water [9]. Two principal factors in maintaining endemicity of intestinal helminthes infections are favorable quantities of the soil and frequent contamination of the environment by human faeces [10]. Their transmission within the community is predominantly related to human habits with regards to eating, defecation, personal hygiene, cleanliness and level of education [11]. Its prevalence in the community can be used as an indication of the conditions of living, environmental sanitation as well as the socio-economic status of the community [12]. Environmental factors such as water supply for domestic and personal hygiene, sanitation and housing, conditions and other factors such as socio-economic, demographic and health-related behavior are known to influence this infection [13].

Despite the prevalence of parasitic worms, anthelmintic drug discovery is very poor [14]. The simple reason is that the nations which suffer most from these tropical diseases have little money to invest in drug discovery or therapy [15]. Therefore it comes as no surprise that the drugs available for human treatment were first developed as veterinary medicine [16]. Not much has been done on the efficacy of anthelmintic drugs in this part of Nigeria and trial has not been reported with Levamisole, and this informed the choice of the drug for this study. This study aimed at determining the prevalence of human parasitic helminthes in relation to age and sex and checking the efficacy of anthelmintic drug Levamisole (Ergamisole ${ }^{\circledR}$ $50 \mathrm{mg}$ ) among primary school pupils in Uzo-Uwani Local Government Area of Enugu State, Nigeria.

\section{Materials and Methods}

\subsection{Description of Study Site}

Uzo-Uwani Local Government Area is found in the Southern part of Enugu State, Nigeria. The people of the area are known for their agricultural activities which are mainly on commercial and peasant basis. It has a population of about one million with children having $45 \%$ of the total population.

\subsection{Investigating Helminthes Infestations in the School Children}

The Primary School (Community Primary School Ogurugu) is located in Uzo-Uwani L.G.A. Ogurugu is located within the lowland coastal plain of Nigeria on a latitude of $12^{\circ} 32^{\prime}$ and $7^{\circ} 7^{\prime}$ North and longitude of $17^{\circ} 40^{\prime}$ and $10^{\circ} 42^{\prime}$ East. This region is in the forest belt of the country with annual rainfall of over $210 \mathrm{~mm}$ per annum and $50^{\circ} \mathrm{F}$ range of temperature.

The School has six classroom blocks with complete roofing and all is painted white. The school is fenced round using local trees; keeping the building away from the surrounding residential houses and commercial cen- ters, but at the back lays a small bush sometimes used indiscriminately as toilet grounds by pupils. The play ground is a loosed soil and the school has two pit latrines, one for boys and the other for the girls. There are few flowers planted as ornamental for beautification.

Ethical Clearance was obtained from the school ethical committee while the children were ordered to obtain their parents consent and participation was voluntary. Sample bottles were given to the volunteers with their identification number attached to them, and the children were told to get their early morning sample while coming to school the next day. The pupils were advised to use the specified method [17]. The stool was to be passed on a clean paper first before scooping a little portion of it into the sample bottle using a dry stick and the bottle was weal corked well. The samples collected on each day were analyzed without any preservation. The stool samples were taken to University of Nigeria Nsukka Zoology laboratory as well as University of Nigeria Health Center Laboratory alternatively for analysis for eggs, larvae and parts of helminthes using the method described by [17].

Three methods were used alternatively, they include saline wet mount, simple sedimentation and saturated salt (Brine) floatation method.The next day the results of the analysis were taken to the school together with Anthelmintic drug (Levamisole) for those with helminthes infection. With the help of the class teachers, the infected children were asked to bring their parents or guardians to school the next day to inform them. Some of the parents honored the invitation. After explaining the mechanism of the drug, a dose of the drug ( $50 \mathrm{mg}$ ) was taken orally using clean water by the researcher as sample, and the children were advised to take theirs in the morning before meal together with a sweetening agent like banana or biscuits which was given to each of them. After two weeks a follow-up test was conducted on the infected pupils to check the efficacy of the anthelmintic drug (Levamisole $50 \mathrm{mg}$ ).

\section{Results}

The result [Figure 1] indicates that a total of 242 pupils
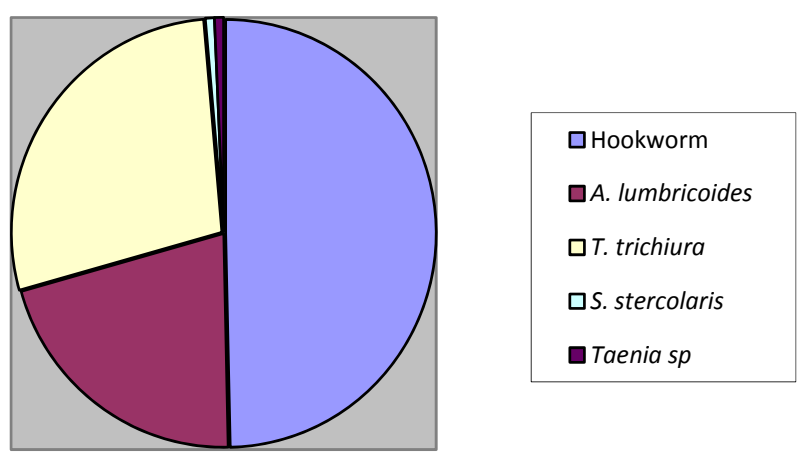

Figure 1. Frequency of Prevalence of various Intestinal Helminthes. 
were randomly sampled and diagnosed for intestinal helminthes infections. 143 (59.1\%) had infections, with Hookworm being the dominant with 71 (49.7\%), followed by Trichuris 40 (28.0\%), Ascaris 30 (20.9\%), S. stercoralis and Taenia sp. had 1 (0.7\%) each. The study also reveals two cases of multiple infections (Poly-parasitism) of which Hookworm and Trichuris occurred in both.

The result of the prevalence of helminthes with respect to sex and age as shown in Table $\mathbf{1}$ indicates that the males recorded a higher prevalence 80 (67.8\%) out of 118 males examined while the female prevalence was 63 (50.8\%) out of 124 females examined. Also the highest levels of infections were recorded among the 5 and 8 yrs groups in both males and females but male highest peak (94.4\%) of infection was recorded among the six years old while the female highest peak (68.8\%) was recorded among the 5 yrs old. Infection also decreases with in- crease in age in both sexes.

The result in Table 2 shows the prevalence of various intestinal helminthes with respect to age and sex. The result shows that hookworm was the most dominant intestinal helminthes 71 (49.7\%). It affects both males and females of all age groups, and this was followed by Trichuris trichiura 40 (28\%) and Ascaris lumbricoides 30 (21\%). There was no significant difference ( $p>0.5$, tcal $=0.672$ ) in helminthes infections with sex.

The result in Table 3 shows the efficacy of Levamisole anthelmintic drug with respect to sex and various age groups. Of 143 children infected with parasitic intestinal helminthes, 120 (83.0\%) received the anthelmintic drug treatment, out of 66 males treated, 54 (81.8\%) lost their worms after treatment and out of 54 females treated $45(83.3 \%)$ lost their worms burden. Hookworm was more sensitive to the drugs, followed by A. lumbricoides and $T$. trichiura while $S$. stercoralis and Taenia $s p$ were

Table 1. Prevalence of helminthes infection with respect to Sex and Age.

\begin{tabular}{|c|c|c|c|c|c|}
\hline \multirow{2}{*}{$\frac{\text { Age (yrs) }}{5}$} & \multirow{2}{*}{$\frac{\text { Total No. examined }}{36}$} & \multicolumn{2}{|c|}{ Male (\%) No Examined No infected } & \multicolumn{2}{|c|}{ Female (\%) No Examined No infected } \\
\hline & & 20 & $16(80.0)$ & 16 & $11(68.8)$ \\
\hline 6 & 40 & 18 & $17(94.4)$ & 22 & $10(45.5)$ \\
\hline 7 & 42 & 21 & 15 (71.4) & 21 & 13 (61.9) \\
\hline 8 & 28 & 13 & $9(69.2)$ & 15 & 8 (53.3) \\
\hline 9 & 25 & 17 & 9 (52.9) & 8 & $4(50.0)$ \\
\hline 10 & 28 & 11 & $6(54.5)$ & 17 & $8(47.1)$ \\
\hline 11 & 32 & 14 & $7(50.0)$ & 18 & 7 (38.9) \\
\hline 12 & 7 & 3 & 1 (33.3) & 4 & $1(25.0)$ \\
\hline 13 & 4 & 1 & $0(0.0)$ & 3 & $1(33.3)$ \\
\hline Total & 242 & 118 & $80(67.8)$ & 124 & $63(50.8)$ \\
\hline
\end{tabular}

Table 2. The Prevalence of various Intestinal Helminthes with Respect to Age and Sex.

\begin{tabular}{|c|c|c|c|c|c|c|c|}
\hline Age grp & No. examined & (\%) No. infected & (\%) Hookworm & (\%) A. lumbricoides & (\%) T. trichiura & (\%) S. stercoralis & (\%) Taenia sp \\
\hline \multirow{3}{*}{$5-6$} & $M=38$ & $33(86.6)$ & 19 (57.6) & $8(24.2)$ & $6(18.2)$ & $0(0.0)$ & $0(0.0)$ \\
\hline & $\mathrm{F}=38$ & $21(55.3)$ & $9(42.9)$ & $6(28.6)$ & $6(28.6)$ & $0(0.0)$ & $0(0.0)$ \\
\hline & $\mathrm{T}=76$ & $54(71.1)$ & 28 (51.9) & $14(25.9)$ & $12(22.2)$ & $0(0.0)$ & $0(0.0)$ \\
\hline \multirow{3}{*}{$7-8$} & $M=34$ & $24(70.6)$ & $13(54.2)$ & $3(12.5)$ & $8(33.3)$ & $0(0.0)$ & $0(0.0)$ \\
\hline & $F=36$ & $21(58.3)$ & $9(42.9)$ & $5(23.8)$ & $7(33.3)$ & $0(0.0)$ & $0(0.0)$ \\
\hline & $\mathrm{T}=70$ & $45(64.3)$ & $22(48.9)$ & $8(17.8)$ & 15 (33.3) & $0(0.0)$ & $0(0.0)$ \\
\hline \multirow{3}{*}{$9-10$} & $M=28$ & $15(53.6)$ & $7(46.7)$ & $5(33.3)$ & $3(20.0)$ & $0(0.0)$ & $0(0.0)$ \\
\hline & $\mathrm{F}=25$ & $12(48.0)$ & $6(50.0)$ & $1(8.3)$ & $5(41.6)$ & $0(0.0)$ & $0(0.0)$ \\
\hline & $\mathrm{T}=53$ & 27 (50.9) & $13(48.1)$ & $6(22.2)$ & $8(29.6)$ & $0(0.0)$ & $0(0.0)$ \\
\hline \multirow{3}{*}{$11>$} & $M=18$ & $8(44.4)$ & $4(50.0)$ & $2(25.0)$ & $2(25.0)$ & $0(0.0)$ & $0(0.0)$ \\
\hline & $F=25$ & $9(36.0)$ & $4(44.4)$ & $0(0.0)$ & $3(33.3)$ & $1(11.1)$ & $1(11.1)$ \\
\hline & $\mathrm{T}=43$ & 17 (39.5) & $8(47.1)$ & $2(11.8)$ & $5(29.4)$ & $1(5.9)$ & $1(5.9)$ \\
\hline Grand total & 242 & 143 (59.1) & 71 (49.7) & $30(21.0)$ & $40(28.0)$ & $1(0.7)$ & $1(0.7)$ \\
\hline
\end{tabular}

$\mathrm{P}>0.5$ (two-tailed), t.cal $=0.672$, t.tab $=2.447$, grp = group, $\mathrm{M}=$ males, $\mathrm{F}=$ females, $\mathrm{T}=$ total, numbers in brackets indicate $\%$ infection while the outer numbers indicate number of cases witnessed. 
Table 3. The prevalence of various intestinal helminthes with age and sex with respect to the efficacy of anthelmintic.

\begin{tabular}{cccccccccccccc}
\hline $\begin{array}{c}\text { Age } \\
(\text { Yrs })\end{array}$ & $\begin{array}{c}\text { No. Infected } \\
(\%)\end{array}$ & $\begin{array}{c}\text { No. treated } \\
(\%)\end{array}$ & \multicolumn{2}{c}{ Hook worms $(\%)$} & \multicolumn{2}{c}{ A. lumbricoides $(\%)$} & \multicolumn{2}{c}{ T. trichiura $(\%)$} & \multicolumn{2}{c}{ S. stercoralis (\%) } & \multicolumn{2}{c}{ Taenia sp (\%) } \\
& & $\mathrm{M}=33$ & $28(84.8)$ & $14(50.0)$ & $1(8.3)$ & $8(28.5)$ & $1(14.3)$ & $6(21.4)$ & $2(33.3)$ & $0(0.0)$ & $0(0.0)$ & $0(0.0)$ & $0(0.0)$ \\
$5-6$ & $\mathrm{~F}=21$ & $19(90.5)$ & $11(57.9)$ & $1(7.7)$ & $5(45.5)$ & $0(0.0)$ & $3(15.8)$ & $1(33.3)$ & $0(0.0)$ & $0(0.0)$ & $0(0.0)$ & $0(0.0)$ \\
& $\mathrm{T}=54$ & $47(87.1)$ & $25(53.2)$ & $2(8.0)$ & $13(27.7)$ & $1(7.7)$ & $9(36.0)$ & $3(33.3)$ & $0(0.0)$ & $0(0.0)$ & $0(0.0)$ & $0(0.0)$ \\
& $\mathrm{M}=24$ & $21(87.5)$ & $11(52.41)$ & $1(9.1)$ & $3(14.3)$ & $1(33.3)$ & $7(33.3)$ & $1(14.3)$ & $0(0.0)$ & $0(0.0)$ & $0(0.0)$ & $0(0.0)$ \\
$7-8$ & $\mathrm{~F}=21$ & $17(81.0)$ & $6(35.3)$ & $2(66.6)$ & $5(29.4)$ & $2(40.0)$ & $6(35.3)$ & $1(16.7)$ & $0(0.0)$ & $0(0.0)$ & $0(0.0)$ & $0(0.0)$ \\
& $\mathrm{T}=45$ & $38(84.4)$ & $17(44.7)$ & $3(17.6)$ & $8(47.1)$ & $3(37.5)$ & $13(34.2)$ & $2(15.2)$ & $0(0.0)$ & $0(0.0)$ & $0(0.0)$ & $0(0.0)$ \\
& $\mathrm{M}=15$ & $10(66.6)$ & $4(40.0)$ & $0(0.0)$ & $3(30.0)$ & $1(33.3)$ & $3(30.0)$ & $2(66.7)$ & $0(0.0)$ & $0(0.0)$ & $0(0.0)$ & $0(0.0)$ \\
$9-10$ & $\mathrm{~F}=12$ & $12(100.0)$ & $6(33.3)$ & $0(0.0)$ & $2(16.6)$ & $0(0.0)$ & $4(33.3)$ & $2(50.0)$ & $0(0.0)$ & $0(0.0)$ & $0(0.0)$ & $0(0.0)$ \\
& $\mathrm{T}=27$ & $22(81.5)$ & $10(45.5)$ & $0(0.0)$ & $5(22.7)$ & $1(20)$ & $7(31.8)$ & $4(57.1)$ & $0(0.0)$ & $0(0.0)$ & $0(0.0)$ & $0(0.0)$ \\
& $\mathrm{M}=8$ & $7(87.5)$ & $3(42.9)$ & $1(33.3)$ & $2(28.6)$ & $0(0.0)$ & $2(28.6)$ & $0(0.0)$ & $0(0.0)$ & $0(0.0)$ & $0(0.0)$ & $0(0.0)$ \\
$11>$ & $\mathrm{F}=9$ & $6(66.7)$ & $2(33.3)$ & $0(0.0)$ & $0(0.0)$ & $0(0.0)$ & $2(33.3)$ & $0(0.0)$ & $1(16.7)$ & $1(100.0)$ & $1(16.7)$ & $1(100.0)$ \\
& $\mathrm{T}=17$ & $13(76.5)$ & $5(38.5)$ & $1(20.0)$ & $2(15.4)$ & $0(0.0)$ & $4(30.7)$ & $0(0.0)$ & $0(0.0)$ & $0(0.0)$ & $0(0.0)$ & $0(0.0)$ \\
Total & 143 & $120(83.0)$ & $57(47.5)$ & $6(10.5)$ & $28(23.3)$ & $4(14.3)$ & $33(27.5)$ & $9(27.3)$ & $1(0.8)$ & $1(100 \%)$ & $1(0.8)$ & $1(100 \%)$ \\
\hline
\end{tabular}

$\mathrm{P}>0.05, \mathrm{DF}=3, \mathrm{X}^{2} \mathrm{tab}=9.488, \mathrm{X}^{2} \mathrm{cal}=80.1$, yrs = years, $\mathrm{M}=$ males, $\mathrm{F}=$ females, $\mathrm{T}=$ total, numbers in brackets indicate \% infection while the outer numbers indicate number of cases witnessed.

not affected by the single dose of Levamisole $50 \mathrm{mg}$ pre body weight. There was a significant difference $(\mathrm{p}<0.05$, $\mathrm{DF}=3, \mathrm{X}^{2} \mathrm{tab}=9.488, \mathrm{X}^{2} \mathrm{cal}=80.1$ ) with respect to the efficacy of anthelmintic Levamisole drugs.

The result in Figure 2 shows the efficacy of Levamisole on intestinal helminthes with respect to age groups in years. The prevalence of infection generally decreases with increase in age, and there was a remarkable reduction in worm burden after treatment with Levamisole in all the age groups.

\section{Discussion}

In this study, the overall prevalence rate of parasitic intestinal helminthes infection among primary school pupils was (59.1\%), and this is similar to the work done by [16] and in contrast with low prevalence rate reported [17-19], and the high prevalence rate obtained by [14,15]. The difference in prevalence could be attributed to seasonal difference, number of samples obtained, age brackets examined and other geographical factors in the studied areas.

The result in Figure 1 revealed that Hookworm had the highest overall prevalence of (49.7\%) followed by Trichuris (28.0\%), Ascaris (20.9\%), S. stercoralis and Taenia sp had $(0.72 \%)$ each. This is similar to works carried out by $[15-17,19,20]$. The study also revealed two cases of multiple or poly-parasitism of which Hookworm and Trichuris occurred in both. The high prevalence of Hookworm may be due to exposure, as children in Government owned primary schools hardly wear protective shoes and those that do, remove theirs while playing within and outside the school premises which encourages the penetration of Hookworm through the skin and subcutaneous tissues [16]. The presence of Ascaris and Trichuris which are transmitted via faecal to oral route indicates that food and water are contaminated with infective eggs of these parasites by any of a number of routes or hand to mouth transmission may occur.

The high prevalence of soil transmitted helminthes (STH) is due to availability of the infective stage of the worm and the damp nature of the soil of the study area. The low rate of Taenia sp is due to the conservative attitude towards meat handling, processing and eating only healthy animals and lack of meat in their meal as a result of poverty. Significant difference in age specific prevalence of infection could be attributed to the unhygienic nature of the younger age groups and the more hygienic and higher level of acquired immunity in the older ones.

On the efficacy of anthelmintic (Levamisole) drug administration (orally), the overall worm burden reduction rate was (82.5\%), and this is similar to work done by [21,23], who had $92.5 \%$ and $85 \%$ respectively and in contrast with work done by [22], who had $100 \%$ efficacy due to combined drugs administration. This shows that no anthelmintic is $100 \%$ efficient and that the pharmaceutical companies should research on the development of new anthelmintic drugs to replace the old ones in use, before these worms will exert total resistance on present day anthelmintic.

The reason for the variation in the reduction rate of each of the helminthes infections to Levamisole drug indicates that a single dose of the drug is not sufficient to reduce some of the worm burden like Strongyloides and Taenia sp. Despite these observations, the efficacy of 
Levamisole in reducing other worms' burden is high.

\section{Conclusion}

In conclusion, it is better to say that prevention is better than cure and health education is the key to the realization of the Nigerian's vision 2020 dream of provision of health for all by the year 2020. Bear in mind that parasitic infections generally are preventable diseases and the control of intestinal helminthes infections revolves around environmental and personal hygiene and effective primary health care system. The Government of the day in Nigeria should map out strategies to educate our pupils on the basic hygiene on community-oriented health programmes.

\section{Acknowledgements}

The authors are grateful to the management and staff University Teaching Hospital (UNTH) Enugu, and the administrative staff of Community Primary School, Ogurugu, Enugu State, Nigeria; for allowing this research work to be conducted in their institutions.

\section{REFERENCES}

[1] L. J. Robertson, D. W. T. Cromption, D. Sanjur and M. C. Neshum, "Trichuris trichuira and the Growth of Primary School Children in panama," Transactions of the Royal Society of Tropical Medicine and Hygiene, Vol. 86, No. 6, 1992, pp. 656-57.

http://dx.doi.org/10.1016/0035-9203(92)90177-E

[2] D. L. Taren and Neshem, "Contribution of Asianasis to Poor Nutritional Status in Children from Chiriqui Province Rep of Panama,” Journal of Parasitology, Vol. 30, 1997, pp. 603-613.

[3] H. Farag, "Intestinal Parasitosis in the Population of the Yemen Arab Republic," Tropical and Geographical Medicine, Vol. 37, 1995, pp. 29-39

[4] W. Peter, "Medical Aspect. Comments and Discussion II. The Relevance of Parasitology to Human Welfare Today," Symposia of the British Society for Parasitology, Vol. 16, 1998, pp. 2171-2175.

[5] A. S. Ghuari and M. Alam, "The Pattern of Pathogenic Intestinal Parasites in Sarghoda Areas A Comprehensive Study," Pakistan Journal of Pathology, Vol. 3, 1992, pp. 99-101.

[6] M. I. Noor, M. I. Sano, C. G. Mohammod, M. Norhayati, A. K. Roham and A. S. Halimah, "Prevalence of Parasitic Infection in Malaysian Oil Palm Estate Workers," The Southeast Asian Journal of Tropical Medicine and Public Health, Vol. 9, No. 2, 1978, pp. 272-276.

[7] W. A. Rahman, "Prevalence of Enterobius vermicularis in Man in Malaysia," Transactions of the Royal Society of Tropical Medicine and Hygiene, Vol. 85, No. 2, 1991, p. 249. http://dx.doi.org/10.1016/0035-9203(91)90043-X

[8] D. R. Arora and B. A. Brij, "Medical Parasitology,” 3rd
Edition, CBS Publishers and Distributors, New Delhi, 2012, pp. 3-6, 233-245.

[9] R. M. Mordi and P. Obile "A Study of Blood and Gastrointestinal Parasites in Edo State,” African Journal of Biochemistry Research, Vol. 6, No. 19, 2007, pp. 2201-2207.

[10] I. O. Emmy-Igbe, E. O. Ekwesianya, C. N. Ukaga, C. I. Eneanyi and C. M. Ajaero, "Prevalence of Intestinal Helminth in Students of Ihiala Local Government Area of Anambra State," Parasitology Research, Vol. 3, No., 2011, pp. 247-249.

[11] J. N. Utzinger, E. K. Goran and H. P. Marti, "Intestinal Amoebiasis, Giardia Lemblia and Geohelminthes; Their Association with Other Intestinal Parasites and Reported Intestinal Symptoms," Transaction of the Royal society of tropical Medicine and Hygiene, Vol. 93, No. 2, 1999, pp. 137-141. http://dx.doi.org/10.1016/S0035-9203(99)90287-0

[12] L. Salvioli, D. A. P. Bundy and A. Tomkin, "Intestinal Parasitic Infection," Transactions of the Royal Society of Tropical Medicine and Hygiene, Vol. 86, No. 4, 1992, pp. 353-354. http://dx.doi.org/10.1016/0035-9203(92)90215-X

[13] M. Zahedi, P. Oothuman, N. N. Sabapathy and N. A. Bakar, "Intestinal Nematode Infections and Efficacy Study of Oxantel-Pyrantel Pamoate among Plantation Workers," Medical Journal of Malaysia, Vol. 7, 1990, pp. 31-37.

[14] O. M. Ukpai, C. O. Ugwu and P. R. James, “The Prevalence of Gastrointestinal Parasites among Primary School Children in Ikwuano L.G.A of Abia State. Nigeria,” Nigerian Journal of Parasitology, Vol. 24, 2003, pp. 129136.

[15] N. C. Eze and S. O. Nzeako, "Intestinal Helminth amongst Hausa and Fulani Settlers in Obinze, Owerri, Imo State, Nigeria,” Nigerian Journal of Parasitology, Vol. 32, No. 2, 2011, pp. 225-229.

[16] F. E. Uwem, "Demographic Characteristics of School children in Government-owned Urban and Rural Schools and an Urban School, in Ikenne L.G.A.Ogun State, Nigeria,” Niger. Nigerian Journal of Parasitology, Vol. 24, No. 30, 2004, pp. 227-228.

[17] D. E. Elekwa and E. I. A. Ikeh, "A Survey of the Incidence of Intestinal Parasites among Primary School Children in Relation to Socio-Economic Factors in Jos," Nigerian Journal of Medical Parasitology, Vol. 31, No. 4, 1996, pp. 60-62.

[18] R. O. Banke, E. A. Omudu, D. A. Ikenwa and E. J. Feese, "Prevalence of Gastrointestinal Parasites in Relation to Availability of Sanitary facilities among Schooling Children in Markurdi, Nigeria," Animal Research International, Vol. 3, No. 2, 2006, pp. 489-493.

[19] C. T. Uneke, O. K. Eze, R. G. Oyibe, N. C. Azu and E. Ali, "Soil-Transmitted Helminthes Infection in School Children in South-Eastern Nigeria,” The Public Health Implication Internet Journal of third World Medicine, Vol. 4, No. 1, 2007, pp. 1-12.

[20] H. L. Smith, "Prospects for the Control of Neglected Tropical Disease by Mass Drug Administrative,” Expert Review of Anti-Infective Therapy, Vol. 7, No. 1, 2009, pp. 
37-56.

http://dx.doi.org/10.1586/14787210.7.1.37

[21] P. J. Hotez, M. J. Bethony, S. L. Oliverra, P. J. Brindley and A. Lukas, "Multivalent Anthelmintic Vaccine to Prevent Hookworm and Schistosomiasis," Expert Review of Vaccines, Vol. 7, No. 6, 2008, pp. 745-752.

http://dx.doi.org/10.1586/14760584.7.6.745

[22] L. Bersissa, “The Efficacy of Albendazole, Tetramisole and Ivermectin against Gastrointestinal Nematodesin
Naturally Infected Goat," Ziway International Journal of Parasitology (Central Ethiopia), Vol. 4, 2010, pp. 77-78.

[23] J. Vercruyssc, et al., "Assessment of the Anthelminthes Efficacy of Albendazole in School Children in Seven Countries Where Soil Transmitted Helminthes are Endemic," PLOS Neglected Tropical Diseases, Vol. 5, No. 3, 2011, p. e948. 